\title{
Efeito do extrato etanólico bruto e das frações da Hyptidendron canum (Pohl ex Benth.) Harley em brânquias de Oreochromis niloticus L.
}

FIUZA, T.S.; SILVA, P.C.; PAULA, J.R.; TRESVENZOL, L.M.F.; FERREIRA, H.D.; SABÓIA-MORAIS, S.M.T. Universidade Federal de Goiás, Caixa Postal 131, Goiânia, GO, CEP: 74001-970, "pjrpaula@gmail.com

\begin{abstract}
RESUMO: Alguns problemas relacionados à criação intensiva de peixes estão mais evidentes devido ao aumento da aquicultura em todo o mundo, destacando-se os distúrbios nutricionais e o aumento de doenças nos sistemas de produção. Com isso as pesquisas envolvendo produtos derivados de plantas vem ganhando espaço nessa área. A Hyptidendron canum é uma planta utilizada na medicina popular como antimalárica, anti-inflamatória, antiulcerativa e anti-hepatotóxica. Objetivou-se, neste trabalho, avaliar os efeitos celulares e teciduais do extrato etanólico bruto e das frações hexano, clorofórmio e acetato de etila da $\mathrm{H}$. canum nas brânquias de Oreochromis niloticus L. Para isso, o extrato etanólico e as frações foram administrados no peixe através da ração. Após 24 horas da ingestão da ração, os peixes foram sacrificados e o segundo arco branquial de cada um foi processado histologicamente e corado com tricômico de Masson e Hematoxilina e Eosina (HE). Pela análise qualitativa das brânquias ao microscópio de luz, observou-se que o extrato bruto e as três frações promoveram, em diferentes intensidades nas lamelas, descamação e destacamento do epitélio respiratório, alteração da curvatura, desorganização do eixo, hiperplasia celular do tecido epitelial interlamelar e vasodilatação nas lamelas e no vaso central do filamento. Os resultados deste experimento mostraram que o extrato etanólico bruto e as três frações de $H$. canum promoveram processos inflamatórios e/ou lesões sistêmicas, dose dependente para O. niloticus.
\end{abstract}

Palavras-chave: Cerrado, plantas medicinais, tilápia, toxicidade.

ABSTRACT: Effect of the crude ethanol extract and fractions of Hyptidendron canum (Pohl ex Benth.) Harley on the gills of Oreochromis niloticus L. Some problems related to intensive fish farming are more evident because of the increased aquaculture worldwide, and we highlight the nutritional disorders and the increase of diseases in the production systems. Thus, research involving plant-derived products has been increasing in this area. The Hyptidendron canum is a plant used in folk medicine as an antimalarial, anti-inflammatory, anti-ulcer and antihepatotoxic agent. This study proposes to evaluate the cellular and tissue effects of the crude ethanol extract and the hexane, chloroform and ethyl acetate fractions of $\mathrm{H}$. canum on the gills of Oreochromis niloticus $L$. The ethanol extract and fractions were administered through the feed of the fish. Twenty-four hours later, the fish were sacrificed and their second gill arch dissected. Histological analyses were performed using Masson's trichrome and Haematoxylin and Eosin (H\&E). The qualitative analysis of the material showed that the crude extract and the three fractions caused varying degrees of peeling and detachment of the lamellar respiratory epithelium, alterations in the curvature and axis of the gill, cell hyperplasia in the interlamellar epithelium and lamellar vasodilation, as well as vasodilation in the central vessel of the filament. The results of this experiment showed that the crude ethanol extract and the three fractions of $H$. canum promoted inflammation and/or systemic lesions, dose dependent, for $O$. niloticus.

Key words: Brazilian Savannah, medicinal plants, tilapia, toxicity.

\section{INTRODUÇÃO}

Em 1990, o Brasil produzia pouco mais que 16 mil toneladas de peixes cultivados. Em 2005, a produção foi de $178.746,5$ toneladas, registrando crescimento, no período, de $1.017 \%$ (IBAMA, 2005).
Isso reflete um substancial aumento na atividade de criação de peixes em cativeiro, acompanhando a tendência mundial.

Apesar de existirem várias espécies de 
peixes nativos com potencial para a atividade da piscicultura, espécies exóticas, como a tilápia, têm demonstrado maior viabilidade econômica, devido ao conhecimento disponível no campo da biologia e nas técnicas de manejo. As tilápias são nativas do continente africano e da Ásia Menor e vivem de forma predominante em águas quentes (Nogueira \& Rodrigues, 2007).

Com o crescimento da piscicultura alguns problemas relacionados à criação intensiva de peixes estão mais evidentes destacando-se os distúrbios nutricionais e o aumento de doenças nos sistemas de produção (Costa, 2003). Esse aumento tem resultado em significativas perdas na aquicultura e no comércio de peixes, afetando o desenvolvimento econômico do setor em muitos países, inclusive no Brasil (Gram et al., 1999). As enfermidades bacterianas são responsáveis por graves mortalidades tanto em peixes de vida livre como nos de criação, e o uso de antibióticos tem apresentado sucesso limitado na prevenção ou cura de infecções. Por outro lado, o uso intensivo dessas substâncias tem levado ao aumento da resistência bacteriana (Verschuere et al., 2000). Portanto, estratégias estão sendo buscadas no intuito de reduzir a multirresistência microbiana, como, por exemplo, o controle do uso dos antimicrobianos, a detecção e a compreensão dos mecanismos genéticos de resistência e a busca de novas substâncias sintéticas ou naturais com atividade antimicrobiana (Nascimento et al., 2000).

Com isso, as pesquisas envolvendo produtos derivados de plantas vêm ganhando espaço na aquicultura devido: ao menor impacto ambiental, à menor toxicidade, aos diversos modos de ação, além de serem menos onerosos na criação (Coimbra et al., 2006). Lu et al. (2002) verificaram que a oferta de ração de Spirulina platensis, como dieta única, durante as fases iniciais do desenvolvimento das larvas de Oreochromis niloticus, foi importante para o crescimento e desenvolvimento normais dessa espécie. Immanuel et al. (2009) verificaram atividade antimicrobiana in vitro dos extratos de Cynodon dactylon, Aegle marmelos, Withania somnifera e Zingiber officinales contra sete patógenos de peixes (Vibrio alginolyticus, Vibrio parahaemolyticus, Vibrio mimicus, Vibrio campbelli, Vibrio vulnificus, Vibrio harveyi e Photobacterium damselae) e aumento dos leucócitos, das atividades fagocíticas e de lisozimas no sangue de Oreochromis mossambicus alimentados com ração contendo $1 \%$ dos extratos dessas plantas. Oliveira et al. (2010) adicionaram extrato de maracujá (Passiflora incarnata) na dieta de tilápias do Nilo jovens, visando diminuir o estresse, e concluíram que o extrato pode ser fornecido na dieta sem prejudicar o consumo alimentar e o crescimento dos animais. Fujimoto et al. (2012) verificaram a eficácia de sementes de abóbora (Cucurbita maxima), desidratadas e moídas, contra nematóides de Astyanax cf. zonatus.

Estudos visando avaliar o potencial das plantas na piscicultura ainda são incipientes, em especial daquelas com uso popular consagrado ou com atividades biológicas já comprovadas em outras espécies.

A Hyptidendron canum (Pohl ex Benth.) Harley é uma planta nativa do Cerrado utilizada na medicina popular como antimalárica, antiinflamatória, anti-ulcerativa e anti-hepatotóxica (Brandão, 1991; Ferri \& Ferreira, 1992). Fiuza et al. (2009) observaram atividade antimicrobiana do extrato etanólico das folhas da $\mathrm{H}$. canum contra bactérias Gram-positivas, Gram-negativas e o fungo Candida albicans.

O óleo essencial obtido das folhas dessa planta apresentou, como constituintes majoritários, o amorpha-4,7(11)-dieno (23,2\%), o biciclogermacreno $(15,9 \%)$ e o $\beta$-cariofileno (13,5\%) (Fiuza et al., 2010). Lemes et al. (2011) isolaram das folhas da $H$. canun o $3 \beta-O-\beta$-galactopiranosilsitosterol, o aldeído ursólico, uma mistura de ácido maslínico e ácido $2 \alpha$-hydroxiursólico, $\alpha$ e $\beta$-amirina, uvaol, eritrodiol, sitosterol, estigmasterol, espatulenol e globulol. As frações hexânica e clorofórmica e os ácidos ursólico e betulínico apresentaram atividade contra leveduras de Paracoccidioides brasiliensis.

Este trabalho teve como objetivo avaliar os efeitos celulares e teciduais do extrato etanólico bruto e das frações da $H$. canum nas brânquias de Oreochromis niloticus L.

\section{MATERIAL E MÉTODO}

\section{Material vegetal}

As folhas da Hyptidendron canum (Pohl ex Benth.) Harley (Lamiaceae) foram coletadas no município de Goiânia-GO, Brasil (16 $16^{\circ} 43^{\prime} 26,1^{\prime \prime} \mathrm{S}$ e $49^{\circ} 15^{\prime} 54,8^{\prime \prime} \mathrm{W}$, a $885 \mathrm{~m}$ de altitude) e a espécie foi identificada pelo Professor Doutor José Realino de Paula, da Universidade Federal de Goiás (UFG). A exsicata foi depositada no herbário dessa instituição, sob o registro UFG/29862.

As folhas foram secas em estufa com circulação de ar a $40^{\circ} \mathrm{C}$ e posteriormente, trituradas em moinho de facas.

\section{frações \\ Obtenção do extrato etanólico bruto e}

O pó das folhas da $H$. canum foi extraído com etanol $96 \%$, na proporção $1: 3$, à temperatura ambiente, sob agitação mecânica por três vezes; os foram extratos reunidos e concentrados em rotaevaporador à temperatura $\leq 40^{\circ} \mathrm{C}$.

Para a obtenção das frações, o extrato

Rev. Bras. PI. Med., Campinas, v.17, n.1, p.1-8, 2015. 
etanólico bruto foi solubilizado em metanol, ao qual se adicionou água destilada $\left(\mathrm{MeOH} / \mathrm{H}_{2} \mathrm{O}\right.$ 7:3). A solução resultante foi extraída por partições líquido/ líquido sucessivas com hexano, clorofórmio e acetato de etila. As frações hexânica, clorofórmica e acetato de etila foram concentradas em rotaevaporador à temperatura $\leq 40^{\circ} \mathrm{C}$ (Ferri, 1996).

\section{Modelo experimental}

As tilápias nilóticas machos foram obtidas no Setor de Piscicultura da Escola de Veterinária da UFG. Os peixes foram pesados e mantidos em tanques de $100 \mathrm{~L}$ supridos com água bem aerada, na proporção de 100L/hora (sistema raceway) e alimentados diariamente às $9 \mathrm{~h}$ e às $16 \mathrm{~h}$ com ração extrusada flutuante Cardume 32 (VB, Brasil) com diâmetro de $4 \mathrm{~mm}$ a $6 \mathrm{~mm}$ e contendo $32 \%$ de proteína.

Cada tilápia, participante do experimento, foi colocada em uma caixa com dois peixes menores, que serviam apenas como companhias, facilitando a adaptação do peixe ao novo ambiente. O período de adaptação foi de uma semana e, durante esse período, o consumo de ração de cada animal foi monitorado e anotado. Diariamente, foram medidos o $\mathrm{pH}$, a temperatura, o teor de amônia e a quantidade de oxigênio da água com o Card Kit da Alfakit (Brasil).

Para a análise experimental foram formados 10 grupos teste de cinco peixes (que ficaram em caixas separadas), com peso médio de $229 \mathrm{~g} \pm 57,8 \mathrm{~g}$ e comprimento de $19,8 \mathrm{~cm}$ a $26,5 \mathrm{~cm}$ e um grupo controle $(n=5)$.

Ao grupo 1 administrou-se $280 \mathrm{mg} / \mathrm{kg}$ do extrato etanólico bruto; aos grupos dois, três e quatro administrou-se a fração hexano nas concentrações de $70 \mathrm{mg} \mathrm{kg}^{-1}, 140 \mathrm{mg} \mathrm{kg}^{-1}, 280 \mathrm{mg} \mathrm{kg}^{-1}$; aos grupos cinco, seis e sete, a fração clorofórmio nas concentrações de $70 \mathrm{mg} \mathrm{kg}^{-1}, 140 \mathrm{mg} \mathrm{kg}^{-1}, 280 \mathrm{mg}$ $\mathrm{kg}^{-1}$; aos grupos oito, nove e dez, a fração acetato de etila nas concentrações de 70 mg kg-1, 140 mg $\mathrm{kg}^{-1}, 280 \mathrm{mg} \mathrm{kg}^{-1}$, respectivamente; o grupo controle recebeu apenas a ração.

A ração com o extrato etanólico bruto e frações foi preparada um dia antes do experimento. Para isso, a quantidade de extrato etanólico de H. canun e das frações (hexânica, clorofórmica e aetato de etila), a ser administrada a cada animal, foi calculada e incorporada aos péletes da ração. O número de péletes, contendo o extrato bruto e frações, foi calculado com base no consumo de péletes diário dos peixes durante a semana de adaptação. No dia do experimento, dois a três péletes contendo o extrato e frações da $H$. canum foram administrados, na dosagem adequada, a cada peixe. Após a comprovação da ingestão desses péletes, os animais foram alimentados normalmente.
As tilápias receberam o extrato etanólico bruto da $H$. canum e as frações em dose única na ração, após um período de 18 horas em jejum. Os peixes foram sacrificados 24 horas depois (BRASIL, 1995). O segundo arco branquial foi dissecado, fixado em formalina neutra, desidratado, incluído em parafina e seccionado com espessura de $3 \mu \mathrm{m}$. Nas análises histológicas foi utilizado o tricômico de Masson e HE. Posteriormente, os cortes foram descalcificados, desidratados e as lâminas montadas em Entellan (Merck -USA). Realizou-se a análise qualitativa e o registro das imagens no fotomicroscópio Olympus $\mathrm{CH}-30$.

Os experimentos foram realizados de acordo com os princípios éticos para a pesquisa animal determinados pelo Colégio Brasileiro de Experimentação Animal (COBEA) e aprovado no Comitê de Ética em Pesquisa do HC/UFG.

\section{RESULTADOS}

\section{frações \\ Obtenção do extrato etanólico bruto e \\ O rendimento do extrato etanólico bruto} obtido com base no pó das folhas da $H$. canum foi de $8,66 \%$. O rendimento das frações com base no extrato bruto foi de $29,61 \%$ para a fração hexano, $23,79 \%$ para a fração clorofórmio e $4,13 \%$ para a fração acetato de etila.

\section{Modelo experimental}

Nos experimentos realizados, o teor de amônia na água permaneceu constante em um valor de $0,5 \mathrm{mg} / \mathrm{L}$; o teor de $\mathrm{O}_{2}$ variou de $5,9 \mathrm{mg} \mathrm{O} / \mathrm{L}$ a $6,5 \mathrm{mg} \mathrm{O}_{2} / \mathrm{L} ; \mathrm{e}$, a temperatura da água, de $23^{\circ} \mathrm{C}$, em média.

Nenhum peixe morreu durante os experimentos.

\section{Microscopia de luz \\ Brânquias - grupo controle}

As brânquias do grupo controle apresentaram epitélio com altura normal, distribuição lamelar padrão com curvatura normal e presença de muco na região interlamelar. Nessa região observaram-se células ricas em mitocôndrias claras e escuras e várias células mucosas. As lamelas estavam revestidas por células pavimentosas e, em seu interior, era possível detectar a presença de capilares sinusóides revestidos com o endotélio e células em pilastra (Figura 1A).

Observou-se no rastelo epitélio estratificado, lâmina basal evidente, células mucosas, algumas com disposição superficial. Foi possível observar, no arco branquial, músculo estriado esquelético, células adiposas, artérias e veias. 


\section{Brânquias - grupo tratado com o extrato etanólico bruto (280 $\left.\mathrm{mg} \mathrm{kg}^{-1}\right)$}

As tilápias que receberam $280 \mathrm{mg} \mathrm{kg}^{-1}$ do extrato bruto da $H$. canum apresentaram nas brânquias descamação e destacamento do epitélio respiratório da base até a região intermédia das lamelas. Os capilares das lamelas e o vaso central do filamento estavam dilatados e congestos de sangue (Figura 1B). Notaram-se perda da curvatura das lamelas e algumas células granulares eosinofílicas (EGCs) no epitélio do espaço interlamelar. Foram verificadas a perda do eixo da lamela e a desorganização do epitélio interlamelar (Tabela 1).

Verificou-se no rastelo epitélio estratificado, constituído por células com núcleo apresentando cromatina condensada e células mucosas, algumas eliminando seu produto de secreção.

\section{Brânquias - grupo tratado com a fração hexano ( $70 \mathrm{mg} \mathrm{kg}^{-1}, 140 \mathrm{mg} \mathrm{kg}^{-1}$ e $280 \mathrm{mg} \mathrm{kg}^{-1}$ ) \\ Os peixes que ingeriram $70 \mathrm{mg} \mathrm{kg}^{-1}$,} $140 \mathrm{mg} \mathrm{kg}^{-1}$ e $280 \mathrm{mg} \mathrm{kg}^{-1}$ da fração hexano da $H$. canum apresentaram rastelo branquial com epitélio cilíndrico estratificado, lâmina basal evidente, células mucosas, algumas com disposição superficial, secretando muco. Notaram-se EGCs no conjuntivo e invadindo o epitélio do rastelo. Observou-se desorganização do conjuntivo. $\mathrm{Na}$ maior concentração identificaram-se várias EGCs no arco branquial.

Detectaram-se, nas brânquias dos peixes que foram tratados com as três concentrações, dilatação e congestão vascular nos capilares das lamelas e no vaso central do filamento (Figura 1C). A dilatação foi mais intensa com o aumento da concentração e, na maior concentração, observouse a presença de telangectasia na região apical das lamelas (Figura 1D). Notaram-se destacamento do epitélio respiratório da base até a região apical da lamela, descamação do epitélio respiratório, hiperplasia no epitélio da região interlamelar, alteração das suas curvaturas e desorganização de seu eixo, e invasão das células interlamelaes em direção ao epitélio respiratório. Verificou-se, no tecido interlamelar, a presença de EGCs (Figura 1C) (Tabela 1).

Nas tilápias que ingeriram $140 \mathrm{mg} \mathrm{kg}^{-1}$ observaram-se EGCs no interior do vaso do filamento. Nas que ingeriram concentrações de $140 \mathrm{mg} \mathrm{kg}^{-1}$ e $280 \mathrm{mg} \mathrm{kg}^{-1}$ notou-se desorganização do epitélio interlamelar (Tabela 1).

Brânquias - grupo tratado com a fração

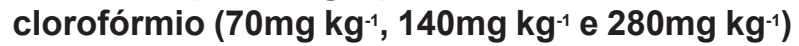

Nas brânquias das tilápias tratadas com $70 \mathrm{mg} \mathrm{kg}^{-1}$, $140 \mathrm{mg} \mathrm{kg}^{-1}$ e $280 \mathrm{mg} \mathrm{kg}^{-1}$ da fração clorofórmio da $H$. canum, observaram-se a presença de várias EGCs, algumas se degranulando, no conjuntivo e invadindo o epitélio do rastelo branquial, grande quantidade de células mucosas nessa região, algumas liberando seu conteúdo na superfície. Notaram-se a presença de EGCs, raros melamomacrófagos agregados, algumas células mucosas e células ricas em mitocôndrias claras e escuras na região interlamelar. Verificaram-se dilatação e congestão vascular no vaso central do filamento e pequena congestão e dilatação na região dos capilares das lamelas, em especial na região apical. Observou-se descamação e destacamento do epitélio respiratório das lamelas, alteração na curvatura das lamelas e desorganização do epitélio interlamelar (Figura 1E) (Tabela 1).

Nos peixes que receberam $140 \mathrm{mg} \mathrm{kg}^{-1}$ e $280 \mathrm{mg} \mathrm{kg}^{-1}$ da fração clorofórmio visualizouse, nas brânquias, hiperplasia no epitélio da região interlamelar. Nos que receberam a maior concentração observaram-se raros neutrófilos no espaço interlamelar (Tabela 1).

\section{Brânquias - grupo tratado com a fração} acetato de etila $\left(70 \mathrm{mg} \mathrm{kg}^{-1}, 140 \mathrm{mg} \mathrm{kg}^{-1}\right.$ e $280 \mathrm{mg}^{-1}$ $\left.\mathbf{k g}^{-1}\right)$

Nas tilápias que receberam $70 \mathrm{mg} \mathrm{kg}^{-1}$, $140 \mathrm{mg} \mathrm{kg}^{-1} \mathrm{e}^{2} 20 \mathrm{mg} \mathrm{kg}^{-1}$ da fração acetato de etila da $H$. canum observaram-se leve congestão e dilatação dos capilares das lamelas e dilatação e congestão vascular no vaso central do filamento. Notou-se hiperplasia no epitélio da região interlamelar, com desorganização do epitélio, alteração na curvatura das lamelas, descamação e destacamento do epitélio respiratório e invasão das células interlamelares em direção ao epitélio respiratório. Verificaram-se a presença de EGCs e células mucosas no espaço interlamelar e o destacamento do epitélio respiratório nas brânquias dos peixes tratados com $140 \mathrm{mg} \mathrm{kg}^{-1}$ e $280 \mathrm{mg} \mathrm{kg}^{-1}$ dessa fração (Tabela 1). Nas que receberam a maior concentração observouse a presença de raros neutrófilos no espaço interlamelar.

Nos peixes que receberam as três concentrações da fração acetato de etila verificouse, na região do rastelo branquial, grande quantidade de células mucosas volumosas, algumas liberando seu conteúdo na superfície. Observaram-se várias EGCs, algumas degranulando no conjuntivo e invadindo o epitélio do rastelo (Figura 1F), e grande quantidade de EGCs no arco branquial nos peixes que ingeriram $140 \mathrm{mg} \mathrm{kg}^{-1}$ e $280 \mathrm{mg} \mathrm{kg}^{-1}$.

Em todos os tratamentos houve relação direta entre o aumento das concentrações das frações e as alterações celulares e teciduais mais severas nas brânquias das tilápias (Tabela 1). 

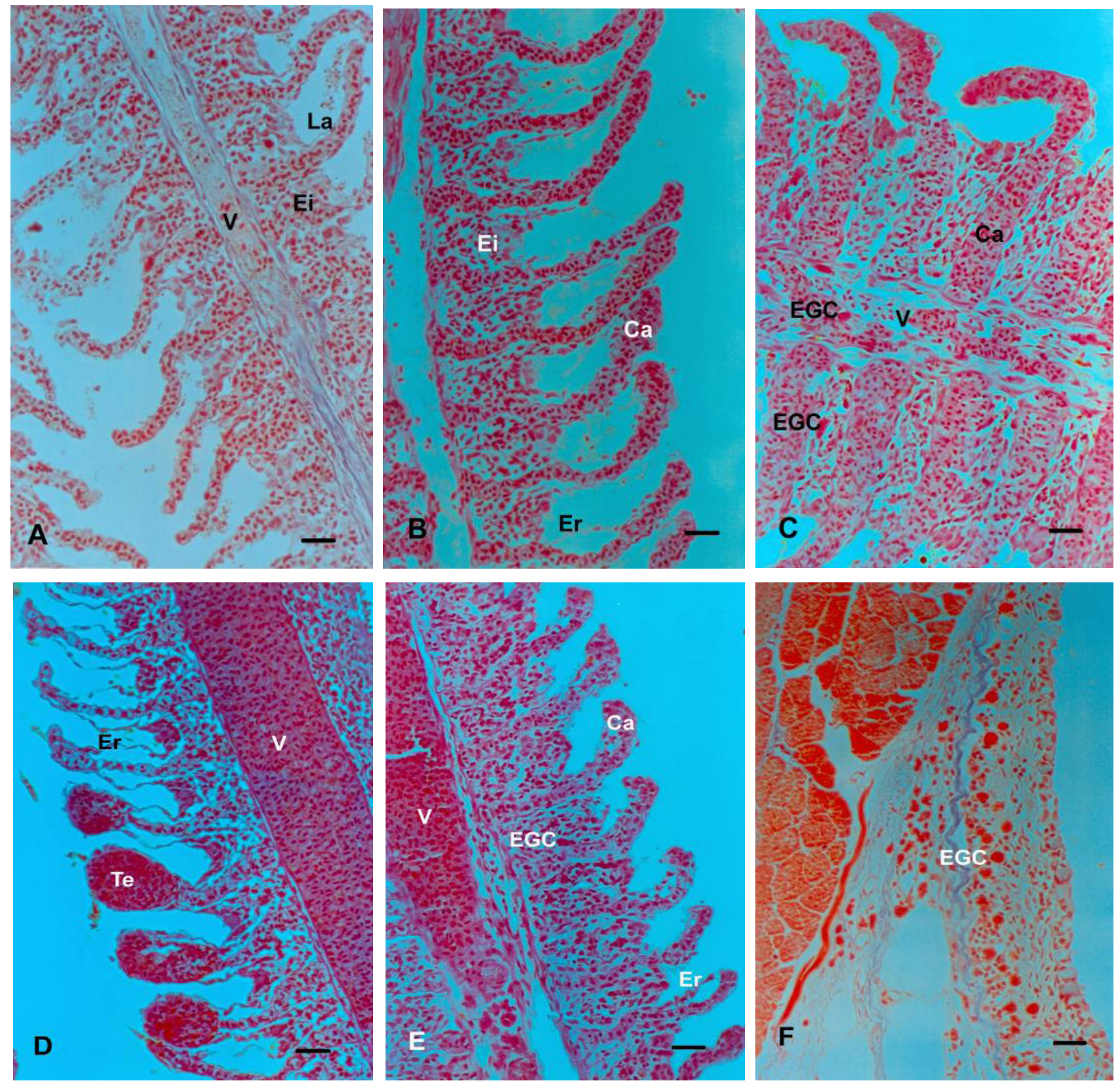

FIGURA 1. Cortes histológicos de brânquias de tilápias nilóticas. A - Região intermediária do filamento de peixe do grupo controle (tratado apenas com a ração). Notam-se lamelas com curvatura e distribuição homogêneas e epitélio interlamelar mantido com altura média (Masson 40x). B - Tratamento com extrato etanólico bruto $280 \mathrm{mg} \mathrm{kg}^{-1}$ da $H$. canum. Verificam-se nas regiões interlamelares modificações na distribuição das células epiteliais com espaços intercelulares, destacamento do epitélio respiratório e congestão sanguínea dos capilares das lamelas e presença de EGCs na região interlamelar e no interior do vaso do filamento (HE). C - Tecidos branquiais expostos a 140 $\mathrm{mg} \mathrm{kg}^{-1}$ fração hexano da $\mathrm{H}$. canum. Observam-se vasodilatação e congestão nos capilares lamelares (HE). D - Filamento branquial de peixe exposto a $280 \mathrm{mg} \mathrm{kg}^{-1}$ da fração hexano da $H$. canum. Notam-se vasodilatação intensa e presença de telangectasia nos capilares lamelares, destacamento do epitélio respiratório e congestão vascular no vaso central do filamento branquial (HE). E - Região intermédia do filamento expostos à $70 \mathrm{mg} \mathrm{kg}^{-1}$ da fração clorofórmio. Verificam-se destacamento do epitélio respiratório das lamelas e vasodilatação intensa do vaso central do filamento e EGCs no epitélio interlamelar (HE). F - Identificou-se grande número de EGCs no conjuntivo e no rastelo branquial em peixes expostos à fração acetato de etila $140 \mathrm{mg} \mathrm{kg}^{-1}$ da H. canum (Masson). $\mathbf{C a}=$ capilar; $\mathbf{E G C}=$ célula granular eosinofílica; $\mathbf{E} \mathbf{i}=$ epitélio interlamelar; $\mathbf{E r}=$ epitélio respiratório; La = lamela; Te = telangectasia; V = vaso central do filamento. Barra $=50 \mu \mathrm{m}$ 


\section{DISCUSSÃO}

No presente estudo verificou-se pequena dilatação e congestão vascular nos capilares das lamelas e no vaso central do filamento nas tilápias que ingeriram o extrato etanólico bruto e as frações clorofórmio e acetato de etila. Essa dilatação foi mais intensa nos peixes que receberam a fração hexano, em relação direta com o aumento da concentração. $\mathrm{Na}$ maior concentração dessa fração observou-se a presença de aneurismas (telangectasia) na região apical das lamelas. Alterações semelhantes foram descritas por Abdel-Tawwab et al. (2007), que observaram, nas brânquias de tilápias do Nilo expostas ao cobre, telangectasia lamelar severa e congestão dos vasos sanguíneos dos filamentos. Garcia-Santos et al. (2007) verificaram vasodilatação das lamelas nas brânquias de tilápias do Nilo expostas ao cádmio. Leonardo et al. (2001) observaram telangectasia e fusão lamelar por infiltrado sanguíneo nas brânquias de larvas de tilápia do Nilo submetidas a níveis insuficientes de vitamina $C$ na ração ou na ausência total dessa vitamina.

As alterações mais frequentes nas brânquias dos peixes que receberam o extrato bruto e as frações foram: descamação e destacamento do epitélio respiratório lamelar; alteração da curvatura e desorganização do eixo lamelar e hiperplasia das células do tecido epitelial interlamelar. Lesões semelhantes foram observadas quando as tilápias foram expostas a agentes tóxicos, como a amônia (Benli \& Köksal, 2005; Benli et al., 2008), o cádmio (Garcia-Santos et al., 2007), quando em deficiência de vitamina C (Leonardo et al., 2001), e quando tratadas com extrato e frações da Eugenia uniflora L. (Fiuza et al., 2011).

Nos peixes que receberam as três frações verificou-se, na região do rastelo branquial, grande quantidade de células mucosas volumosas, algumas liberando seu conteúdo na superfície. Observaramse várias EGCs, algumas degranulando no conjuntivo e invadindo o epitélio do rastelo, grande quantidade de EGCs no arco branquial e algumas no espaço interlamelar. Nos que receberam fração clorofórmio notaram-se alguns neutrófilos no

TABELA 1. Alterações patológicas nas brânquias de O. niloticus após tratamento com extrato bruto e frações hexano, acetato de etila e clorofórmio das folhas de $H$. canum

\begin{tabular}{|c|c|c|c|c|c|c|c|c|}
\hline $\begin{array}{l}\text { Tratamentos } \\
\text { Folhas de H. }\end{array}$ & & & $\begin{array}{r}\text { Alterações patoló } \\
\qquad(\mathrm{n}=5\end{array}$ & $\begin{array}{l}\text { gicas nas brâ } \\
\text { para cada tra }\end{array}$ & $\begin{array}{l}\text { nquias de } 0 . \text { nilc } \\
\text { tamento) }\end{array}$ & ticus & & \\
\hline $\begin{array}{l}\text { Extrato } \\
\text { etanólico } \\
\text { bruto }\end{array}$ & $\begin{array}{l}\text { Descamação e } \\
\text { destacamento } \\
\text { do epitélio } \\
\text { respiratório }\end{array}$ & $\begin{array}{c}\text { Dilatação } \\
\text { vascular e } \\
\text { congestão } \\
\text { sanguínea }\end{array}$ & $\begin{array}{c}\text { Desorganização } \\
\text { do epitélio } \\
\text { interlamelar }\end{array}$ & $\begin{array}{c}\text { Alteração } \\
\text { da } \\
\text { curvatura } \\
\text { das lamelas }\end{array}$ & $\begin{array}{c}\text { Invasão } \\
\text { das células } \\
\text { interlamelares } \\
\text { em direção } \\
\text { ao epitélio } \\
\text { respiratório }\end{array}$ & $\begin{array}{l}\text { Células } \\
\text { mucosas }\end{array}$ & EGCs & Telangectasia \\
\hline $\begin{array}{l}\text { 280mg kg-1 } \\
\text { Fração } \\
\text { hexano }\end{array}$ & 1 & 2 & 1 & 1 & 0 & 1 & 1 & 0 \\
\hline $280 \mathrm{mg} \mathrm{kg}^{-1}$ & 3 & 3 & 1 & 2 & 3 & 2 & 2 & 2 \\
\hline $140 \mathrm{mg} \mathrm{kg}^{-1}$ & 2 & 2 & 1 & 1 & 2 & 2 & 2 & 0 \\
\hline $\begin{array}{c}\text { 70mg kg-1 } \\
\text { Fração } \\
\text { clorofórmio }\end{array}$ & 1 & 1 & 0 & 1 & 1 & 1 & 2 & 0 \\
\hline $280 \mathrm{mg} \mathrm{kg}^{-1}$ & 2 & 1 & 3 & 1 & 3 & 3 & 2 & 0 \\
\hline $140 \mathrm{mg} \mathrm{kg}^{-1}$ & 1 & 1 & 3 & 1 & 3 & 2 & 1 & 0 \\
\hline $\begin{array}{l}\text { 70mg kg-1 } \\
\text { Fração } \\
\text { acetato de } \\
\text { etila }\end{array}$ & 1 & 1 & 3 & 1 & 3 & 1 & 1 & 0 \\
\hline $280 \mathrm{mg} \mathrm{kg}^{-1}$ & 2 & 1 & 3 & 1 & 3 & 3 & 1 & 0 \\
\hline $140 \mathrm{mg} \mathrm{kg}^{-1}$ & 2 & 1 & 2 & 1 & 2 & 2 & 1 & 0 \\
\hline $70 \mathrm{mg} \mathrm{kg}^{-1}$ & 0 & 1 & 2 & 1 & 0 & 1 & 0 & 0 \\
\hline
\end{tabular}

Legenda: 0 = patologia ausente; 1 - patologia presente esporadicamente (em menos de $20 \%$ da lâmina; 2 - patologia afetando $50 \%$ da lamela; 3- patologia afetando mais de $80 \%$ da lamela. EGCs - células granulares eosinofílicas. A estimativa da porcentagem das patologias foi feita em relação ao total das lamelas secundárias presentes em uma lâmina. 
espaço interlamelar. Funcionalmente, as EGCs dos teleósteos são similares aos mastócitos dos mamíferos, isto é, são mediadores do processo inflamatório. A degranulação das EGCs é seguida por uma reação inflamatória com vasodilatação (Reite \& Evensen, 2006).

Estudos sobre o efeito de plantas em tilápias nilóticas já foram realizados por outros autores. Taiwo et al. (2005) testaram o efeito do extrato aquoso das folhas de Aloe vera L. em vários órgãos do peixe, inclusive as brânquias, e concluíram que essa planta possui substâncias tóxicas potentes para esses animais. Entre as alterações observadas nas brânquias, os pesquisadores destacaram a degeneração vacuolar dos filamentos e necrose das células epiteliais e a infiltração heterofílica da submucosa branquial. Ayotunde \& Ofem (2008) observaram nas brânquias de tilápias nilóticas expostas ao extrato aquoso de Carica papaya L. degeneração de filamentos e lamelas, vacuolização dos arcos branquiais e remoção total das lamelas.

Os resultados desse experimento mostraram que o extrato etanólico bruto e as três frações de $H$. canum promoveram processos inflamatórios e/ ou lesões sistêmicas, dose dependente para $O$. niloticus.

\section{REFERÊNCIAS}

ABDEL-TAWWAB, M. et al. The use of calcium preexposure as a protective agent against environmental copper toxicity for juvenile Nile tilapia, Oreochromis niloticus (L.). Aquaculture, v.264, n.1-4, p.236-46, 2007.

AYOTUNDE, E.O.; OFEM, B.O. Acute and chronic toxicity of pawpaw (Carica papaya) seed powder to adult Nile tilapia (Oreochromis niloticus Linne 1757). African Journal of Biotechnology, v.7, n.13, p.2265-74, 2008.

BENLI A, Ç.K.; KÖKSAL, G. The acute toxicity of ammonia on tilapia (Oreochromis niloticus L.) larvae and fingerlings. Turkish Journal of Veterinary and Animal Science, v.29, p.339-44, 2005.

BENLI, A.Ç.K.; KÖKSA, L.G.; ÖZKUL, A. Subletal ammonia exposure of Nile tilapia (Oreochromis niloticus L.): Effects on gill, liver and kidney histology. Chemosphere, v.72, n.9, p.1355-58, 2008.

BRANDÃO, M. Plantas medicinais do Cerrado mineiro. Informativo Agropecuário, v.15, p.15-20, 1991.

BRASIL. Ministério da Agricultura, do Abastecimento e da Reforma Agrária. Sistema de análise de riscos e pontos críticos na indústria da pesca: manual de procedimentos. Rio de Janeiro: SENAI/DN/DET, 1995. 46p.

COIMBRA J.L. et al. Toxicidade de extratos vegetais a Scutellonema bradys. Pesquisa Agropecuária Brasileira, v. 41, n.7, p.1209-11, 2006.

COSTA, A.B. Caracterização de bactérias do complexo Aeromonas isoladas de peixes de água doce e sua atividade patogênica. 2003, 54p. Tese (Doutorado em
Ciência Animal e Pastagens) - Universidade de São Paulo, Piracicaba, SP.

CUNHA, A.P. Farmacognosia e fitoquímica. Lisboa: Fundação Calouste Gulbenkian, 2005. 670 p.

FERRI, P.H.; FERREIRA, H.D. Fitoquímica das folhas de Hyptis Benth. Semana de Química, Goiânia, GO, p.1-32, 1992.

FERRI, P.H. Química de Produtos Naturais: métodos gerais. In: DI STASI, L.C. (Ed.). Plantas medicinais arte e ciências. Um guia de estudo interdisciplinar. São Paulo: Editora Universidade Estadual Paulista, 1996. p.129-56.

FIUZA, T.S. et al. Antimicrobial activity of the crude ethanol extract from Hyptidendron canum leaves. Pharmaceutical Biology, v. 47,.n.7, p. 640-44, 2009.

FIUZA, T.S. et al. Composition and chemical variability in the essential oils of Hyptidendron canum (Pohl ex Benth.) Harley. Journal of Essential Oil Research, v. 22, p. 159-63, 2010.

FIUZA, T.S. et al. Análise tecidual e celular das brânquias de Oreochromis niloticus L. tratadas com extrato etanólico bruto e frações das folhas da pitanga (Eugenia uniflora L.) - Myrtaceae. Revista Brasileira de Plantas Medicinais, v.13, n.4, p.389-95, 2011.

FUJIMOTO, R.Y. et al. Controle alternativo de helmintos de Astyanax cf. zonatus utilizando fitoterapia com sementes de abóbora (Cucurbita maxima) e mamão (Carica papaya). Pesquisa Veterinaria. Brasileira, v. 32, n.1, p.5-10, 2012.

GARCIA-SANTOS, S. et al. Alterações histológicas em brânquias de tilápia nilotica Oreochromis niloticus causadas pelo cádmio. Arquivo Brasileiro de Medicina Veterinária e Zootecnia, v.59, n.2, p.376-81, 2007.

GRAM, L. et al. Inhibition of Vibrio anguillarum by Pseudomonas flurescens $\mathrm{AH} 2$, a possible probiotic treatment of fish. Applied and Environmental Microbiology, v.65, n.3, p.969-73, 1999.

IBAMA - INSTITUTO BRASILEIRO DE MEIO AMBIENTE. Estatística da Pesca. Disponível em: < www.ibama. gov.br>. Acesso em outubro de 2005.

IMMANUEL, G. et al. Dietary medicinal plant extracts improve growth, immune activity and survival of tilapia Oreochromis mossambicus. Journal of Fish Biology, v.74, p. 1462-75, 2009.

LEMES, G.F. et al. Constituintes químicos de Hyptidendron canum (Pohl ex Benth.) R. Harley (LAMIACEAE). Química Nova, v.34, n.1, p.39-42, 2011.

LEONARDO, J.M.L.O. et al. Histologia das brânquias de larvas da tilápia do Nilo, Oreochromis niloticus (L.), de origem tailandesa, submetidas a diferentes níveis de vitamina C. Maringá, v.23, n.4, p.863-70, 2001.

LU, J. et al. Acceptability of raw Spirulina platensis by larval tilapia Oreochromis niloticus. Fisheries Science, v. 68, p. 51-58, 2002.

NASCIMENTO, G.G.F. et al. Antibacterial activity of plant extracts and phytochemicals on antibiotic-resistant bacteria. Brazilian Journal of Microbiology, v.31, n.4, p.247-56, 2000.

NOGUEIRA, A.C.; RODRIGUES, T. Criação de tilápias em tanques-rede. Salvador: Sebrae Bahia, 2007. 23 p.

OLIVEIRA, R.H.F. et al. O extrato de maracujá sobre a morfometria de hepatócitos da tilápia do Nilo. Ciência Rural, v.40, n.12, p.2562-67, 2010.

Rev. Bras. PI. Med., Campinas, v.17, n.1, p.1-8, 2015. 
REITE, O.B.; EVENSEN, O. Inflammatory cells of teleostean fish: A review focusing on mast cells/ eosinophilic granule cells and rodlet cells. Fish \& Shellfish Immunology, v.20, n.2, p. 192-208, 2006.

TAIWO, V.O. et al. Consumption of aqueous extract of raw Aloe vera leaves: Histophathological and Biochemical studies in rat and tilapia. African Journal of Biomedical Research, v.8, n.5, p.169-78, 2005.

VERSCHUERE, L. et al. Selected bacterial strains protect Artemia spp. from the pathogenic effects of Vibrio proteolyticus CW8T2. Applied and Environmental Microbiology, v.66, n.3, p.1139-46, 2000. 